\title{
UC experts can lead on carbon dioxide removal
}

\section{Through technology demonstration and policy engagement, UC ANR specialists, advisors and AES faculty can support California's ambitions to remove $\mathrm{CO}_{2}$ from the atmosphere.}

Daniel L. Sanchez, Assistant Cooperative Extension Specialist, Department of Environmental Science, Policy, and Management, UC Berkeley Benjamin Z. Houlton, Director, UC Davis John Muir Institute of the Environment

Whendee Silver, Professor, Department of Environmental Science, Policy, and Management, UC Berkeley

Online: https://doi.org/10.3733/ ca.2019a0009

\begin{abstract}
arbon dioxide removal (CDR) technologies, also known as negative emissions technologies, appear critical to achieving California's ambitious climate change mitigation goals (Cameron et al. 2017). Negative carbon dioxide $\left(\mathrm{CO}_{2}\right)$ emissions cannot be achieved by reducing greenhouse gas (GHG) emissions alone; rather, both emissions reductions and pathways to atmospheric $\mathrm{CO}_{2}$ extraction are needed to achieve this desired outcome. Yet CDR technologies lack both technical and commercial maturity, and are not yet deployed at industrial scales. In response, numerous
\end{abstract}

state government and nongovernmental organizations in California have taken early steps to support research, development and demonstration (RD\&D) of carbon removal (California Air Resources Board et al. 2018; Forest Climate Action Team 2018).

There are two general approaches to CDR, biological and engineered (fig. 1). Biological approaches enhance or manipulate natural sinks for $\mathrm{CO}_{2}$ to store more carbon, typically on land. Engineered approaches apply chemical and physical processes to capture and reliably convert or store $\mathrm{CO}_{2}$ (Sanchez, Amador, et al. 2018).

\section{B | O L O G I C A L}

E N G I N E ERE D

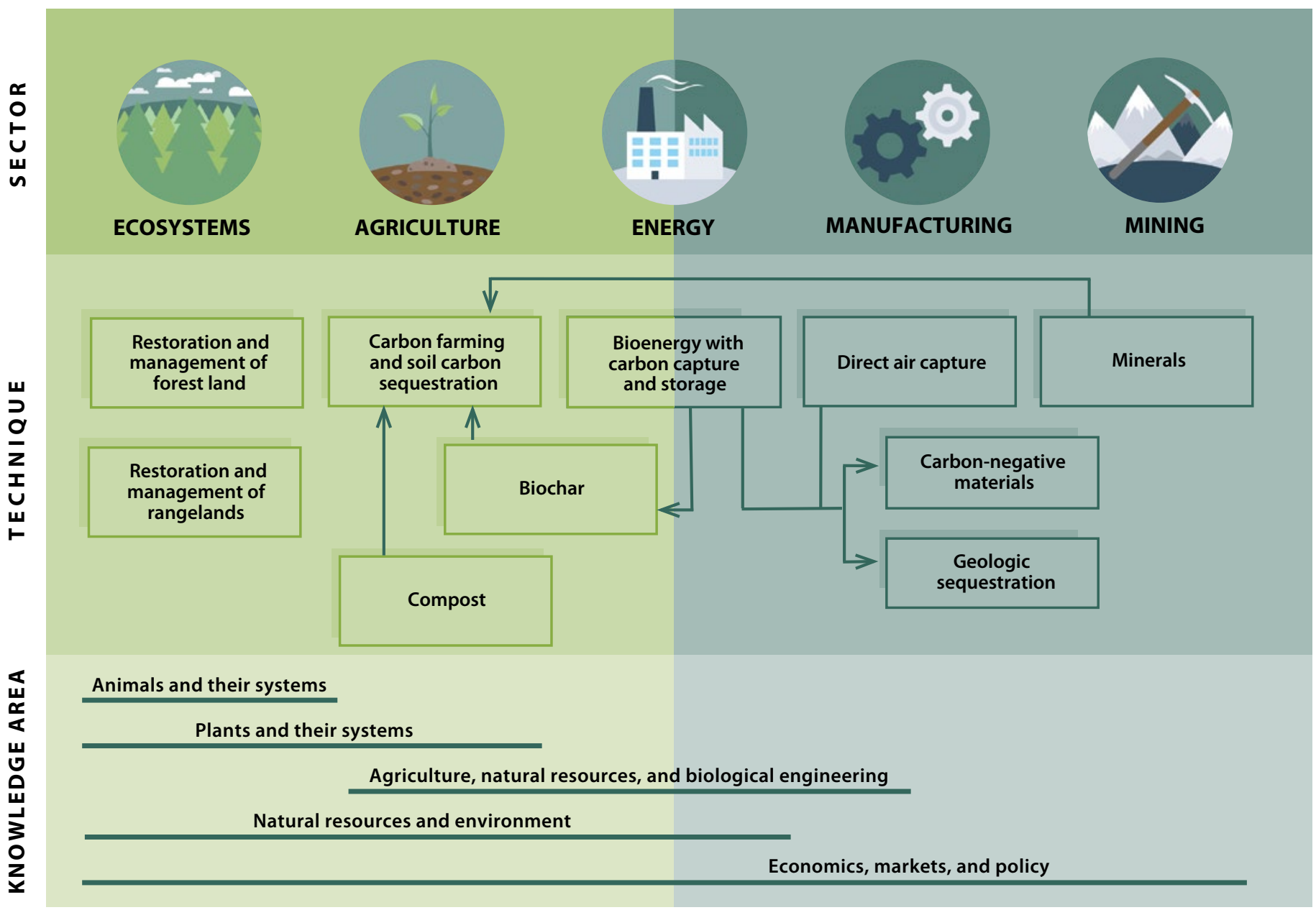

FIG. 1. Sectors, techniques and UC ANR knowledge areas relevant to carbon removal technologies. Knowledge areas drawn from UC ANR's Taxonomy and Personnel System. Adapted from Sanchez, Amador, et al. 2018. 
Biological and engineered approaches to $\mathrm{CO}_{2}$ removal can be deployed alongside other climate change responses to reduce emissions, avoid climate impacts, and promote economic development within

\section{Overview of the Working Lands Innovation Center (WLIC)}

Partners: University of California, Davis; University of California, Berkeley; California State University, East Bay; Lawrence Berkeley National Laboratory; University of California, Merced

Funding: $\$ 4.7$ million

Objective: To scale and sustain $\mathrm{CO}_{2}$ capture and $\mathrm{GHG}$ emissions reductions by deploying a suite of cutting-edge soil amendment technologies, driving substantial co-benefits for California growers, ranchers, tribes, communities, the economy and environment. This project will increase understanding of the mechanisms and potential for carbon sequestration in soil.

Research: WLIC's research is focused on three technologies to capture $\mathrm{CO}_{2}$ with co-benefits: rock amendments in cropland and rangelands, compost applications to cropland and rangeland soil, and demonstration of combinations of compost, rocks and biochar. WLIC will also conduct geospatial model analysis to identify best practices for scaling carbon removal statewide. These soil amendment technologies have not yet been tested together across the state.

Benefits: WLIC's demonstrations will (i) maintain and protect agricultural economy in rural areas; (ii) promote opportunities for tribal nations through collaborative partnerships; (iii) create cleaner air and water in the Central Valley and Imperial Valley; (iv) redesign organic waste streams, converting problems into solutions; (v) restore soil health and protect the environment; (vi) enhance agricultural workforce development; (vii) increase the affordability of healthy food options; (viii) create opportunities for ranchers and farmers to financially benefit from soil restoration practices and GHG reductions; and (ix) develop new business opportunities in the area of soil amendment production, distribution and innovation.

Engagement: Work with commercial partners (Almond Board of California, compost and biochar producers), landowners across California (commercial and family farmers and ranchers), the USDA, UC Agriculture and Natural Resources, small business development (Larta Institute), tribes and the American Carbon Registry to translate science findings into action, and scale technologies within and outside of California. Annual and sub-annual farmer showcase events will highlight opportunities for farmers and ranchers to engage in research and deploy technologies.
California. In this way, CDR offers an array of useful co-benefits for the economy, people and the planet.

UC Cooperative Extension (UCCE) researchers and Agricultural Experiment Station (AES)-appointed faculty hold considerable expertise in carbon removal technologies, whether in working lands management, carbon sequestration, land restoration or forest products (fig. 1). They form an essential go-between from basic research to applied outcomes, working with faculty and student researchers to create material gains for citizens and society. Moreover, UCCE's transdisciplinary approach to applied research, outreach and engagement can help commercialize CDR, positioning California for continued technology leadership. When combined with UC's world-leading education and research community and system-wide initiatives in climate neutrality, UCCE has the potential to catalyze research discoveries into negative emissions. Here, we provide an overview of existing and potential technology demonstration and policy engagement activities within UCCE relevant to carbon removal in California. We argue that specialists and advisors have a unique and unprecedented role in supporting California's ambitions to remove $\mathrm{CO}_{2}$ from the air.

\section{Leadership in development and deployment}

UCCE has a long history of commercializing and disseminating new technologies to farmers, ranchers and natural resource managers (Humiston 2015). These include technologies that enhance export competitiveness, environmental sustainability and resilience to extreme weather while promoting economic opportunities for farmers, ranchers and rural communities. California has long benefited from these successful new industries, healthy ecosystems and sustainably managed landscapes. CDR deployment can benefit from UCCE's wide array of external partners, projects and resources built over the last century.

UCCE plays an essential role in the "innovation ecosystem" for CDR. Innovation is commonly conceptualized as a process involving invention, innovation and diffusion, where users produce more or better outputs from the same inputs (Nemet et al. 2018). These performance improvements and cost reductions can generate better outcomes, such as increased $\mathrm{CO}_{2}$ removal, reduced environmental side effects, and greater public acceptance. As innovation progresses from research, to demonstration, scale up, niche markets and large-scale deployment, UCCE can interface with the most relevant stakeholders supporting implementation. These extension audiences include academics, entrepreneurs, resource managers, technology developers, policymakers and community members (fig. 2).

$\mathrm{CO}_{2}$ removal also aligns with an emerging strategic priority within UCCE: mobilizing to address the threat of climate change (Grantham et al. 2017). Since 2015, UC Agriculture and Natural Resources (UC ANR) has supported a climate change program team, which is building capacity within UCCE to better address climate change

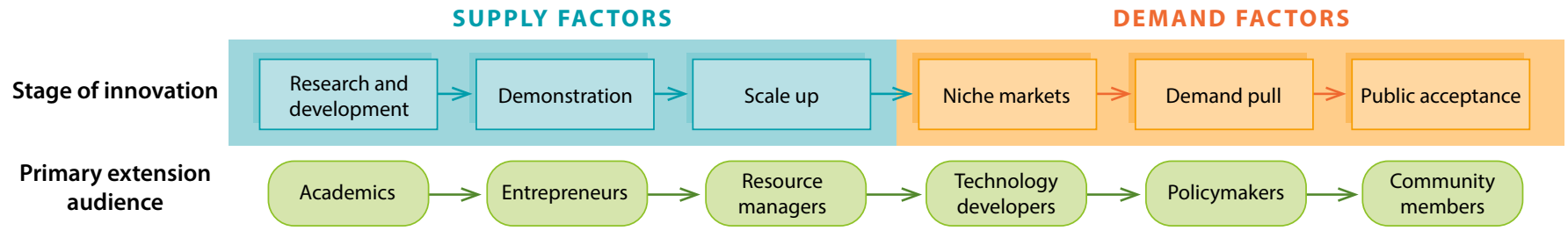

FIG. 2. Stages of innovation and primary extension audiences. Supply factors reduce the costs of innovation through education and research. Demand factors increase the returns to innovation by increasing the demand for new technologies. Adapted from Nemet et al. 2018. 
impacts and adaptation challenges. This team, which consists of advisors and specialists across the state, is working to identify the tools, resources and information that UC ANR extension personnel need to engage more effectively with climate change.

Recently, UCCE has taken several steps to advance research and outreach on carbon removal in California. Taken together, these projects and initiatives demonstrate UCCE's unique ability to advance research and outreach around CDR. They include:

- C4S Working Lands Innovation Center Catalyzing Negative Carbon Emissions: A center to scale and sustain $\mathrm{CO}_{2}$ capture and GHG emissions reductions by deploying a suite of cuttingedge soil amendment technologies, including compost, pulverized rock and biochar. This project will increase understanding of the mechanisms and potential for carbon sequestration in soil, while driving substantial co-benefits for California growers, ranchers, tribes, communities, the economy and environment (see sidebar). This innovation ecosystem, borne from the California Collaborative for Climate Change Solutions (C4S), was recently awarded $\$ 4.7$ million by the California Strategic Growth Council via revenues generated from the state's cap and trade fund.

- Carbon farming: UCCE Sonoma County and Marin County have worked with local resource conservation districts to support carbon farm planning, a whole farm approach to optimizing carbon capture on working landscapes. Working with landowners, advisors developed plans for grazing management, compost application, soil sampling and impact assessment. Ultimately, landowners were able to increase soil carbon by implementing Natural Resources Conservation Service practices and tools, thereby removing $\mathrm{CO}_{2}$ from the atmosphere. UCCE Marin County has supported additional projects that sequester $\mathrm{CO}_{2}$ through riparian restoration.

\section{- Joint Institute for Wood Products Innovation:}

This UC-CSU joint institute will provide guidance, research and analysis to support expansion of the forest products sector in California in a manner that increases economic drivers for healthy forests. The work of the Institute will support sustainability, forest resilience, long-term carbon storage and local economies, and serve as a center for analysis, testing and outreach in California. The Joint Institute was established by the California Board of Forestry and Fire Protection pursuant to Executive Order B-52-18.

Each of the projects is transdisciplinary, applied and collaborative - three hallmarks of UCCE activities.

Moving forward, UCCE can continue to fill this unique role in state-sponsored research and demonstration programs.

\begin{tabular}{|c|c|c|c|c|}
\hline Overarching policies & E.O. B-55-18 & $\begin{array}{l}\text { NWL implementa } \\
\text { tion plan }\end{array}$ & $\begin{array}{l}\text { Strategic Growth } \\
\text { Council funding }\end{array}$ & S.B. 100 \\
\hline $\begin{array}{l}\text { Technology } \\
\text { pathways }\end{array}$ & $\begin{array}{l}\text { Low-carbon } \\
\text { fuels standard }\end{array}$ & Buy Clean California & & \\
\hline Biomass utilization & $\begin{array}{l}\text { Renewable } \\
\text { natural gas } \\
\text { procurement }\end{array}$ & $\begin{array}{l}\text { Wood product } \\
\text { innovation }\end{array}$ & $\begin{array}{l}\text { Biomass-to-power } \\
\text { mandates }\end{array}$ & \\
\hline Natural pathways & $\begin{array}{l}\text { Healthy Soils } \\
\text { Initiative }\end{array}$ & Offset programs & $\begin{array}{l}\text { Land restoration \& } \\
\text { conservation }\end{array}$ & $\begin{array}{l}2030 \text { NWL } \\
\text { goals }\end{array}$ \\
\hline \multicolumn{5}{|l|}{ Federal policies } \\
\hline & Tax policy & $\begin{array}{l}\text { Renewable Fuel } \\
\text { Standard }\end{array}$ & Farm Bill & $\begin{array}{l}\text { R\&D } \\
\text { policy }\end{array}$ \\
\hline
\end{tabular}

FIG. 3. Taxonomy of CDR policies in California and supportive federal policy.

\section{Implementing and improving policy}

UCCE can also bring its vast technical and relational knowledge to bear on policy for CDR (Gupta et al. 2019). Extension can provide multiple services to the policy process: technical expertise, objectivity, partnership building, stakeholder-oriented research, and community empowerment. UCCE's ability to foster deliberative dialogue within diverse communities can build experience and trust in CDR approaches.

To date, California has developed numerous policies that can support carbon removal technologies (fig. 3). These span high-level climate goals, research and development, purchasing mandates, sectoral GHG standards, carbon offsets, technology demonstration and land conservation programs. Below, we briefly highlight several policies that hold promise for promoting CDR.

\section{High-level goals}

\section{- Executive Order B-55-18 to Achieve Carbon}

Neutrality sets a new statewide goal to "achieve carbon neutrality as soon as possible, and no later than 2045, and achieve and maintain net negative emissions thereafter." While this goal has not been codified into law by the legislature, executive orders such as this one have historically been the first step towards legally binding policy.

- 2030 Natural and Working Lands Climate Change Implementation Plan poses an increase in state-led conservation, restoration and management activities from two to five times above current levels. The plan acknowledges that state efforts to conserve, restore and manage natural and working lands play a pivotal role in achieving deep GHG reductions.

- S.B. 100 sets an ambitious goal for $100 \%$ of California's electricity to be supplied by renewable energy and zero-carbon resources, including generators with carbon capture and sequestration. 


\section{Technology pathways}

- Low Carbon Fuel Standard (LCFS) carbon capture and storage protocol enables carbon capture and sequestration projects associated with fuel production to access low-carbon fuel standard credits, which provide financial incentive for lower-carbon fuels. Carbon capture projects are eligible regardless of where the projects are located. Direct air capture technologies are also eligible to participate.

- Buy Clean California (A.B. 262) calls for California state government to procure low-carbon goods. The program applies to carbon steel rebar, flat glass, mineral wool board insulation and structural steel, but not yet to cement and other harvested wood products that can store or sequester $\mathrm{CO}_{2}$.

- Biopower and renewable natural gas procurement programs set mandates for procurement of electricity from high-hazard waste biomass sources (E-4805), small-scale biomass power plants (E4922) and biomethane (S.B. 1440). Many of these technologies can remove $\mathrm{CO}_{2}$ from the atmosphere.

\section{R\&D policy}

- Strategic Growth Council innovation funding has been directed towards natural and technological carbon removal solutions.

- California Energy Commission energy RD\&D programs advance innovation on low-carbon fuels and electricity. Their work has supported research and analysis on carbon-negative energy systems, biogas, biochar and other CDR technologies.

- Joint Institute for Wood Products Innovation, established by the Board of Forestry, advances development of new wood products, which can sequester $\mathrm{CO}_{2}$ and drive ecologically beneficial forest management.

\section{Ecological pathways}

- Healthy Soils Initiative provides technical assistance and grants for farmers and ranchers to adopt soil carbon sequestering practices and measurement and verification plans.

- California Climate Investments Forest Health Grant Program restores forest health to reduce GHGs, promote the longterm storage of carbon in forest trees, minimize the loss of forest carbon from severe wildfire and further the state's climate change goals.

- U.S. and tropical forest programs provide carbon offsets from the state's cap and trade system for practices that increase in-forest carbon storage or reduce tropical deforestation, respectively.

- Sustainable Agricultural Lands Conservation Program has provided over \$120 million in grant funding to reduce GHGs associated with land conversion.

Finally, California-based efforts can interface with federal CDR policy. These include tax credits for carbon sequestration (Section 45Q), the federal Renewable Fuels Standard, agriculture policies set in the Farm Bill, and research, development and demonstration (RD\&D) programs for agriculture and energy projects. For instance, operators of biorefineries and anaerobic digesters that capture and sequester their $\mathrm{CO}_{2}$ emissions can qualify both for federal tax credits and the LCFS, should they sell their low-carbon fuels in California (Sanchez, Johnson, et al. 2018).
As California continues to innovate in CDR policy, UCCE can fill multiple roles. First, it can work with AES-appointed faculty and other researchers in the UCs and UC national labs to test, perfect and demonstrate new research breakthroughs in CDR. Second, it can contribute its own expertise to develop new policies, particularly those that leverage California's ecosystems for carbon removal. Third, it can help spread information about existing incentives to landowners and resource managers considering CDR. Finally, it can offer feedback to policymakers on existing policies based both on policy-relevant research and on the experiences of rural Californians. These roles span UCCE's unique mix of technical and relational knowledge.

\section{A vision for Cooperative Extension}

UCCE efforts to develop and deploy CDR technologies have the opportunity to scale across and outside of California. UC is an active participant in the $\mathrm{C} 4 \mathrm{~S}$, which aims to accelerate the translation of research into practical climate solutions at the national and global level. C4S brings together UC, CSU, UC national labs, Stanford, Caltech and USC, and has prioritized development of CDR technologies. Outside of the state, UC has launched the University Climate Change Coalition (UC3), a coalition of leading North American research universities that will prototype a collaborative model designed to help local communities achieve their climate goals. UC3 now consists of 26 university partners outside California. UC3 provides a way to scale the UC's Carbon Neutrality Initiative to other jurisdictions, both domestically and abroad. Given its expertise and support within and beyond the state, UCCE is already a leader in creating practical winwins toward the carbon-negative economy, with the potential to do even more through these and other efforts in the future. CA

\section{References}

California Air Resources Board, California Environmental Protection Agency, California Department of Food and Agricul ture, et al. 2018. California 2030 Natural and Working Lands Climate Change Implementation Plan Concept Paper.

Cameron DR, Marvin DC, Remucal JM, et al. 2017. Ecosystem management and land conservation can substantially contribute to California's climate mitigation goals. Proc Natl Acad Sci 114:12833-38. https://doi.org/10.1073/ pnas. 1707811114

Forest Climate Action Team. 2018. Forest Carbon Plan: managing our forest landscapes in a changing climate.

Grantham T, Kearns F, Kocher S, et al. 2017. Building climate change resilience in California through UC Cooperative Extension. Calif Agr 71:197-200. https:// doi.org/10.3733/ca.2017a0045
Gupta C, Campbell D, Cole-Weiss A. 2019. Cooperative Extension can better frame its value by emphasizing policy relationships. Calif Agr 73:11-18. https:// doi.org/10.3733/ca.2018a0040

Humiston G. 2015. UC ANR: The original incubator. Calif Agr 69:206-7. https:// doi.org/10.3733/ca.v069n04p206

Nemet GF, Callaghan MW, Creutzig F, et al. 2018. Negative emissions-Part 3: Innovation and upscaling. Environ Res Lett 13:063003. https://doi org/10.1088/1748-9326/aabff4

Sanchez DL, Amador G, Funk J, et al. 2018. Federal research, development, and demonstration priorities for carbon dioxide removal in the United States. Environ Res Lett 13:015005. https://doi. org/10.1088/1748-9326/aaa08f

Sanchez DL, Johnson N, McCoy ST et al. 2018. Near-term deployment of carbon capture and sequestration from biorefineries in the United States. Proc Natl Acad Sci 115:4875-80. https://doi. org/10.1073/pnas.1719695115 